\title{
Polymyxin B Alleviates Angiotensin II-Induced Stress Fiber Formation and Cellular Hypertrophy
}

\author{
Kwang-Seok Oh${ }^{1,2}$, Jeong Hyun Lee ${ }^{1}$, Byung Koo Oh${ }^{1}$, Jihye Mun'1, Byung Kil Park ${ }^{1,3}$, \\ Byung Ho Lee ${ }^{1,3 *}$ \\ ${ }^{1}$ Research Center for Drug Discovery Technology, Korea Research Institute of Chemical Technology, Daejeon, \\ South Korea \\ ${ }^{2}$ Department of Medicinal and Pharmaceutical Chemistry, University of Science and Technology, Daejeon, \\ South Korea \\ ${ }^{3}$ Graduate School of New Drug Discovery and Development, Chungnam National University, Daejeon, South \\ Korea \\ Email:
}

Received 13 July 2014; revised 4 August 2014; accepted 10 August 2014

Copyright (C) 2014 by authors and Scientific Research Publishing Inc.

This work is licensed under the Creative Commons Attribution International License (CC BY).

http://creativecommons.org/licenses/by/4.0/

(c) () Open Access

\section{Abstract}

Polymyxin B is widely used antibiotic in the clinic for resistant Gram-negative infections. In addition, polymyxin B-immobilized hemoperfusion cartridge has been used for endotoxin removal therapy in patients with septic shock. The aim of this study was to investigate the anti-fibrotic and anti-cellular hypertrophic effects of polymyxin $B$, and further to explore its possible mechanism. Polymyxin B $(3,10 \mu \mathrm{M})$ significantly inhibited stress fiber formation induced by angiotensin II (Ang II) in rat heart-derived H9c2 cells. Furthermore, polymyxin B (1 - $10 \mu \mathrm{M})$ showed a potent inhibitory effect on Ang II-induced cellular hypertrophy in H9c2 cells. Under the mechanism study, the inhibitory activities of polymyxin $B$ against kinases involved in cellular hypertrophy such as AKT1, CAMK, GRK5, GSK3 $\beta$, MLCK, PKC, PKD2, AMPK, ROCK2, p70S6K, SGK1 were evaluated. Polymyxin $B$ possesses a potent $G$ protein related kinase 5 (GKR5) inhibitory activity with IC $_{50}$ value of $1.1 \mu \mathrm{M}$, and has an ATP non-competitive inhibitory mode. Taken together, these results indicate that polymyxin B alleviates Ang II-induced stress fiber formation and cellular hypertrophy, and propose that one mechanism underlying these effects involves inhibition of the GRK5 pathway.

\section{Keywords}

Polymyxin B, GRK5, Angiotensin II, Actin Stress Fiber, Cellular Hypertrophy

\footnotetext{
${ }^{*}$ Corresponding author.
}

How to cite this paper: Oh, K.-S., Lee, J.H., Oh, B.K., Mun, J., Park, B.K. and Lee, B.H. (2014) Polymyxin B Alleviates Angiotensin II-Induced Stress Fiber Formation and Cellular Hypertrophy. Pharmacology \& Pharmacy, 5, 903-910. 


\section{Introduction}

Physiological and pathological adaptations of cell are responses to stress that allow cells to modulate their structure and lead to escape injury. Stress fiber formation as well as cellular hypertrophy belongs to the adaptive cell response to various stimuli. However, inappropriate regulation of stress fiber formation and hypertrophic cell growth is directly involved in numerous pathological situations, including cardiovascular disease and cancer [1] [2]. In particular, cardiomyocyte hypertrophy through subsequent alterations in actin dynamics was commonly observed in heart failure including cardiac remodeling after myocardial infarction [3] [4]. Thus, the suppression of stress fiber formation and cellular hypertrophy are considered a promising pharmacological strategy for cardiovascular diseases, and a number of inhibitors have been developed accordingly [5] [6].

Polymyxin B is a cyclic polypeptide antibiotic produced by the soil bacterium Paenibacillus polymixa [7]. It has re-emerged in clinical practice due to increasing prevalence and incidence of nosocomial infections caused by multidrug-resistance Gram-negative infections [8]. Polymyxin B can alter bacterial outer-membrane permeability and lead to disruption of membrane integrity. In addition to its antibiotic function, polymyxin B is widely applied in a medical device to remove circulating endotoxin by adsorption such as direct hemoperfusion cartridge for prevention of septic shock after various surgeries [9] [10]. Other biological effects of polymyxin B so far include induction of apoptosis [11], modulation of ATP-sensitive potassium channels [12], and inhibition of sarcoplasmic reticulum $\mathrm{Ca}^{2+}$-ATPase [13], superoxide anion release [14] and insulin secretion [15]. To date, however, there is little information about the pharmacological actions of polymyxin B related to cardiovascular diseases, especially in conditions such as cardiac fibrosis and hypertrophy. Therefore, in the present study, we investigate the anti-fibrotic as well as anti-hypertrophic effects of polymyxin B in H9c2 cells and further explore the possible mechanism underlying these effects of polymyxin B.

\section{Materials and Methods}

\subsection{Materials}

Polymyxin B sulfate, [N-[4-amino-1-[[1-[[4-amino-1-oxo-1-[[6,9,18-tris(2-aminoethyl)-15-benzyl-3-(1-hydroxyethyl)-12-(2-methylpropyl)-2,5,8,11,14,17,20-heptaoxo-1,4,7,10,13,16,19-heptazacyclotricos-21-yl]amino] butan2-yl]amino]-3-hydroxy-1-oxobutan-2-yl]amino]-1-oxobutan-2-yl]-6-methyloctanamide, and staurosproine were purchased from Sigma-Aldrich (St. Louis, MO, USA). Human recombinant G protein related kinase 5 (GRK5) was purchased from Invitrogen (Invitrogen, Carlsbad, CA, USA). The fluorescent peptide substrate (ULightHiston H3 derived peptide) and time-resolved fluorescence resonance energy transfer (TR-FRET) Screening Kit were obtained from PerkinElmer (Waltham, MA, USA). 384-Well white flat-bottom plates were purchased from Corning Life Sciences (Lowell, MA, USA). Dulbecco's modified Eagle's medium (DMEM), fetal bovine serum, and antibiotics were purchased from GIBCO BRL (Grand Island, NY, USA).

\subsection{Cell Culture}

Rat heart-derived H9c2 cells were purchased from the American Type Culture Collection (ATCC, Rockville, MD, USA) and maintained at $1 \times 10^{6}$ cells $/ \mathrm{ml}$ in DMEM supplemented with $10 \%$ fetal bovine serum, penicillin $\mathrm{G}(100 \mathrm{IU} / \mathrm{ml})$, streptomycin $(100 \mu \mathrm{g} / \mathrm{ml})$, and L-glutamine $(2 \mathrm{mM})$ at $37^{\circ} \mathrm{C}$ humidified atmosphere containing $5 \% \mathrm{CO}_{2}$ and $95 \%$ ambient air. Cells were then starved in serum free media for $3 \mathrm{~h}$ and stimulated with $0.3 \mu \mathrm{M}$ Ang II in the presence or absence of polymyxin B $(1-30 \mu \mathrm{M})$ at the indicated times. Stock solutions of polymyxin $\mathrm{B}$ were prepared in dimethyl sulfoxide, and the maximum concentration of dimethyl sulfoxide in experimental media was $0.1 \%$. Cells were cultured $\left(37^{\circ} \mathrm{C}, 5 \% \mathrm{CO}_{2}\right)$ in a 16-well chamber slide (for immunofluorescent staining) or in 6-well plates (for cellular hypertrophy). Cells were used at the following passage numbers: H9c2 cells (P3-15).

\subsection{Immunofluorescent Staining for F-Actin Stress Fiber Formation}

H9c2 cells were plated on a chamber slide (Thermo Fisher Scientific Inc., Rochester, NY, USA) at $1 \times 10^{5}$ cells/ml. After preincubation with or without polymyxin B $(1-30 \mu \mathrm{M})$ for $1 \mathrm{~h}$, cells were treated with Ang II $(0.3 \mu \mathrm{M})$ for $2 \mathrm{~h}$ and fixed with $4 \%$ paraformaldehyde for $20 \mathrm{~min}$. Fixed cells were incubated with $0.5 \%$ Triton $\mathrm{X}-100$ for $5 \mathrm{~min}$ at $-20^{\circ} \mathrm{C}$ and blocked with $1 \%$ bovine serum albumin for $30 \mathrm{~min}$. Cells were then probed with Alexa fluor 586 phalloidin (Invitrogen, Carlsbad, CA, USA, diluted 1:1000) for $30 \mathrm{~min}$ at room temperature in 
the dark, washed with phosphate-buffered saline solution three times, and stained with Hoechst 33342 dye for 2 min. Fluorescent images were obtained under a fluorescence microscope at $400 \times$ magnification (Nikon, Tokyo, Japan). Actin stress fiber formation was visualized using an Alexa fluor 586 phalloidin. The same fields were counter stained with Hoechst 33342 dye for the location of the nuclei. For image analysis, at least 40 cells per group were collected and determined red intensity using Image-Pro PLUS software (Media Cybernetics, Silver Spring, MD, USA). The data shown represent image analysis from 6 independent images per group.

\subsection{Measurement of Cellular Hypertrophy}

Cellular hypertrophy was measured from H9c2 cells treated with Ang II $(0.3 \mu \mathrm{M})$ for 4 consecutive days. Cells were seeded at a density of $3 \times 10^{4}$ cells per 35-mm dish of 6-well plates and cultured for $24 \mathrm{~h}$ in DMEM containing 10\% fetal bovine serum. After washing with serum-free medium (DMEM without serum), cells were treated with polymyxin B $(1-30 \mu \mathrm{M})$ under serum-free conditions for $24 \mathrm{~h}$. Cells were then treated with potential hypertrophic agonists, Ang II $(0.3 \mu \mathrm{M})$ in quiescence medium (DMEM with $0.5 \%$ fetal bovine serum) with or without a fresh supply of polymyxin B. Following this, cells were incubated for another 4 days at $37^{\circ} \mathrm{C}$ in a humidified atmosphere containing $5 \% \mathrm{CO}_{2}$ to induce hypertrophic responses. After inducing cellular hypertrophy, adherent cells were fixed with $1 \%$ glutaraldehyde (Sigma-Aldrich) in phosphate buffered saline for 30 min and stained with $0.1 \%$ Crystal violet (Sigma-Aldrich) for $10 \mathrm{~min}$. Random photographs were taken from each sample using a digital camera attached to an inverted microscope (Nikon) for analysis. At least 140 individual cells per each group were measured to determine the cell size using Image-Pro PLUS software (Media Cybernetics, Silver Spring, MD, USA). The data shown represent image analysis from 12 - 14 independent images per group.

\subsection{Inhibitory Activities of Polymyxin B against Kinases Involved in Cellular Hypertrophy}

Under the mechanism study, the inhibitory activities of polymyxin B at the concentration of $10 \mu \mathrm{M}$ were determined by panel screen services in EurofinsPanlabs (Test No.: AB23230; Taipei, Taiwan) using radioactive kinase assays against 10 distinct kinases involved in cellular hypertrophy such as AKT1, calcium/calmodulin-dependent protein kinase (CAMK), glycogen synthase kinase $3 \beta$ (GSK3 $\beta$ ), mysin light-chain kinase (MLCK), protein kinase $\mathrm{C}$ (PKC), protein kinase D2 (PKD2), AMP-activated protein kinase (AMPK), rho-associated protein kinase 2 (ROCK2), phosphoprotein 70 ribosomal protein S6 kinase (p70S6K), serum/glucocorticoid-regulated kinase 1 (SGK1).

\subsection{Time-Resolved Fluorescence Resonance Energy Transfer Assay for GRK5}

The inhibitory activity of polymyxin B against GRK5 was measured using LANCE ${ }^{\circledR}$-TR-FRET (time-resolved fluorescence resonance energy transfer; PerkinElmer, Waltham, MA, USA). In order to assume the similar sensitivity compare to the other kinase assays, the ATP concentration $(10 \mu \mathrm{M})$ was adjusted to equal $\mathrm{K}_{\mathrm{m}}$ and the concentration of GRK5 $(0.5 \mu \mathrm{g} / \mathrm{ml})$ was used at an $\mathrm{EC}_{50}$ value. ULight-Histon H3 derived peptide (PerkinElmer; $80 \mathrm{nM}$ ) was used as a substrate for GRK5. The kinase reaction buffer contained $50 \mathrm{mM}$ HEPES (pH 7.5), 10 $\mathrm{mMMgCl}_{2}, 1 \mathrm{mM}$ EGTA, $2 \mathrm{mM}$ DTT, $0.01 \%$ Tween 20 . The total reaction volume was $10 \mu \mathrm{l}$ and test compounds were preincubated with enzyme for $10 \mathrm{~min}$ before adding peptide substrate and ATP. Kinase reactions were conducted for $1 \mathrm{~h}$ at room temperature in standard 384-well plates (Corning Life Sciences, Lowell, MA, USA) and then $10 \mu \mathrm{l}$ of detection mixture including $10 \mathrm{mM}$ EDTA and $1 \mu \mathrm{M}$ europium-tagged antibody (PerkinElmer) was added to reaction plates $1 \mathrm{~h}$ before reading. Following the addition of all reagents for reaction, the TR-FRET signal was detected using an EnVision multi-label reader (PerkinElmer) with compatible setup: excitation at $340 \mathrm{~nm}$, emission at $615 \mathrm{~nm}$ and $665 \mathrm{~nm}$ with a $100 \mu$ s delay time.

\subsection{Statistical Analysis}

All values are expressed as means \pm SDs. Data were analyzed by one-way analysis of variance (ANOVA), followed by Dunnett's test for multiple comparisons (Sigma Stat, Jandel Co., San Rafael, CA, USA). Concentration-response curves were analyzed by nonlinear regression using PRISM version 5.0 (GraphPad Software Inc., La Jolla, CA, USA), and the $\mathrm{IC}_{50}$ value of polymyxin B (the concentration required to reduce the TR-FRET count to $50 \%$ of the positive control) was calculated. In all comparisons, statistical significance was accepted for 
p values of $<0.05$.

\section{Results}

\subsection{Effects of Polymyxin B on Actin Stress Fiber Formation}

To evaluate the cellular effects of polymyxin B, actin stress fiber formation assay was performed. As shown in Figure 1, treatment with Ang II $(0.3 \mu \mathrm{M})$ alone (Control $(+))$ for $2 \mathrm{~h}$ caused an increase of actin stress fiber formation by $86.4 \%$. Increased number of stress fibers in Ang II-stimulated H9c2 cells was significantly decreased by pretreatment with polymyxin $\mathrm{B}(\mathrm{p}<0.05$ at $3,10 \mu \mathrm{M})$.

\subsection{Effects of Polymyxin B on Cellular Hypertrophy}

In H9c2 cells treated with Ang II $(0.3 \mu \mathrm{M})$ alone (Control $(+))$ for 4 consecutive days, cell size was significantly increased by approximately $1.51 \pm 0.17$ times (Figure 2). The Ang II-induced cellular hypertrophy was significantly inhibited by pretreatment with polymyxin B $(\mathrm{p}<0.05$ at $1-10 \mu \mathrm{M})$ in a concentration-dependent manner.

\subsection{Inhibitory Effects of Polymyxin B on Kinases Involved in Cellular Hypertrophy}

Under the mechanism study, the inhibitory activities of polymyxin B at the concentration of $10 \mu \mathrm{M}$ were determined for kinases (AKT1, CAMK, GRK5, GSK3 $\beta$, MLCK, PKC, PKD2, AMPK, ROCK2, p70S6K, SGK1) which involved with cellular hypertrophy. As shown in Table 1, polymyxin B showed potent inhibitory effects on the GRK5, with mild inhibitory effects on the PKD2, and no off-target inhibition with other kinases.

\subsection{Inhibitory Effects of Polymyxin B on GRK5}

The inhibitory activity of polymyxin B against GRK5 were measured using a kinase assay based on LANCE ${ }^{\circledR}$ TR-FRET, which involves specific interactions between proprietary europium-tagged antibody and ULight covalent phosphorylated moieties. Phosphosubstrate-europium-tagged antibody binding events can be directly quantified and expressed as TR-FRET counts, which reflect the amount of GRK5-induced phosphorylation of

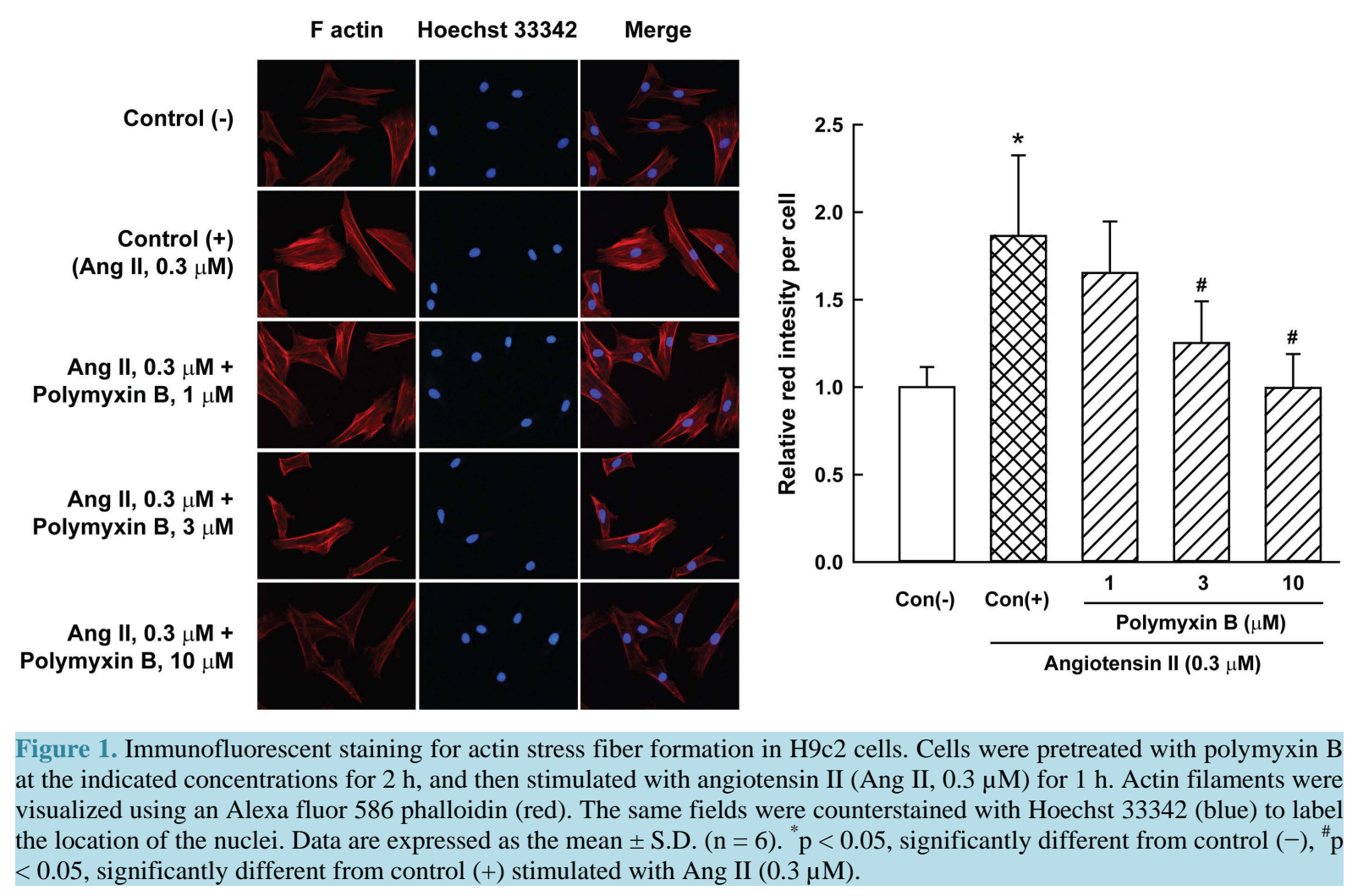




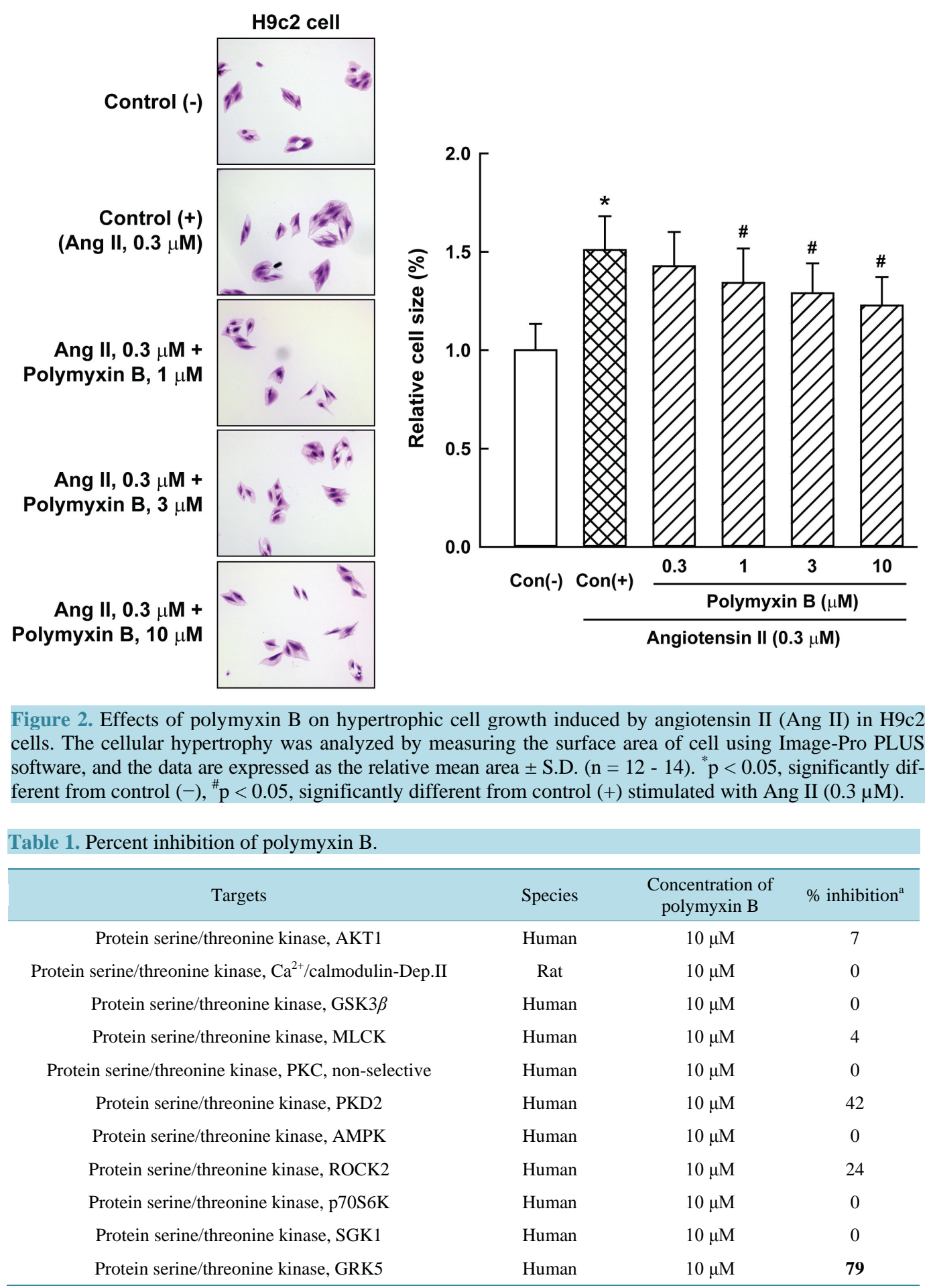

a The inhibitory activities of polymyxin B at the concentration of $10 \mu \mathrm{M}$ were determined by panel screen services in EurofinsPanlabs (Test No.: AB23230; Taipei, Taiwan) using radioactive kinase assays. The results were expressed as a percentage inhibition relative to the control reaction without an inhibitor. Results with more than $50 \%$ of inhibition are bold typeface.

substrates. The assay conditions of GRK5-LANCE-TR-FRET assays were verified using staurosporine as a reference compound ( $\mathrm{IC}_{50}$ values: $43.5 \mathrm{nM}$ ), which agreed with the $\mathrm{IC}_{50}$ values obtained from Invitrogen group through Lanta screening $(90 \mathrm{nM})$. As shown in Figure 3(a), polymyxin B inhibited the GRK5-induced TRFRET counts in a concentration-dependent manner, and provided IC $_{50}$ value of $1.1 \mu \mathrm{M}$. 
In the inhibition mode studies, double reciprocal plots of $1 / v$ versus $1 /$ [ATP] were performed using various concentrations of ATP (5 - $80 \mu \mathrm{M})$, GRK5 $(0.5 \mu \mathrm{g} / \mathrm{ml})$, and ULight-Histon H3 substrate $(80 \mathrm{nM})$ in the presence or absence of polymyxin B. The initial rate $\mathrm{v}$ was defined as rate of phospho-substrate transfer $(\mathrm{nM} / \mathrm{min})$. As shown in Figure 3(b), the addition of polymyxin B increased the apparent the $V_{\max }$ value for ATP of GRK5 in a concentration dependent manner without any change in the $K_{m}$ values. These results indicate that polymyxin $B$ behavesas an ATP non-competitive inhibitor of GRK5.

\section{Discussion}

Polymyxin B is a cyclic polypeptide antibiotic that clinically used in the treatment of multidrug-resistant pathogens and medical device to remove circulating endotoxin by adsorption. In addition to its antimicrobial function and endotoxin-neutralizing activity, many indirect or direct biological activities of polymyxin B were reported such as protective effects against hepatic ischemia/reperfusion injury in rat with obstructive jaundice [16], cardioprotective effects on rabbit heart with ischemic insults by modulation of ATP-sensitive potassium channels [17], and suppression of endotoxin-induced insulin hypersecretion in pancreatic islets [18].

In the present study, we found that polymyxin B markedly inhibited Ang II-induced actin stress fiber formation in rat heart-derived H9c2 cells. Furthermore, in the cellular hypertrophy study, Ang II-induced enlargement of cell size was significantly suppressed by polymyxin B in a concentration-dependent manner. Indeed, pathological stress fiber formation stimulates hypertrophy of myocardial cells, and this process is tightly regulated by intracellular signaling pathways connected to several protein kinases [19]. Thus, we hypothesized that the anti-fibrotic and anti-cellular hypertrophic effect of polymyxin B may be due to blocking the protein kinase dependent signaling pathway involved in cardiac hypertrophy. Under the mechanism study, the inhibitory activities of polymyxin B against kinases involved in cellular hypertrophy such as AKT1, CAMK, GRK5, GSK3 $\beta$, MLCK, PKC, PKD2, AMPK, ROCK2, p70S6K, SGK1 were evaluated. Among them, polymyxin B showed potent inhibitory effects on the GRK5, with mild inhibitory effects on the related kinase PKD2, and no off-target inhibition with other kinases. It is well established that phosphorylation of class II HDAC5 (histone deacetylase 5) by regulation of PKD is an important event in the transcriptional regulation of cardiac gene reprogramming that results in the hypertrophic growth response [20]. It is also well known that GRK5 has particular relevance to the development of cardiac hypertrophy and heart failure [21]. In cultured vascular smooth muscle cells and rat aorta, Ang II-induced GRK5 up-regulation is considered as a molecular mechanism for long-term regulation [22]. GRK5 contains a phosphatidylinositol 4,5-bisphosphate binding domain, which contributes to constitutive

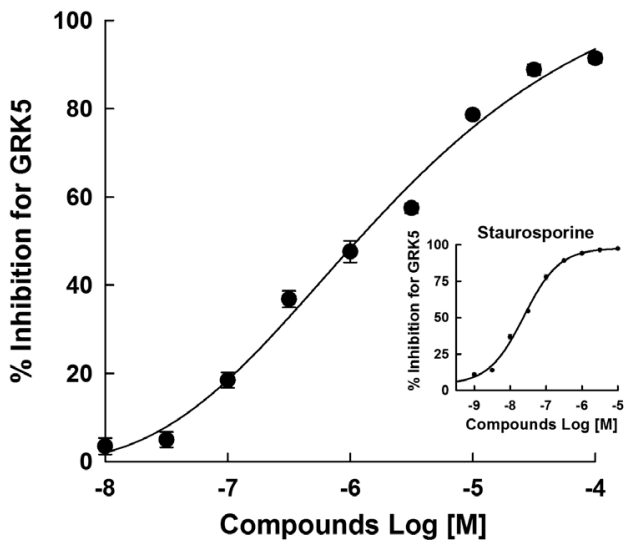

(a)

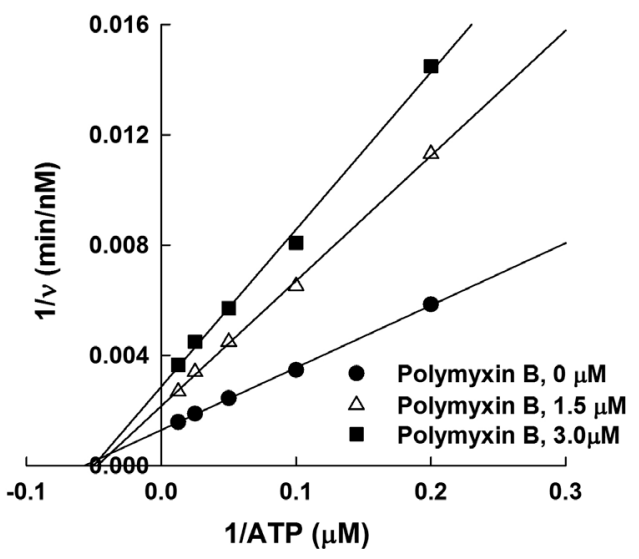

(b)

Figure 3. Inhibitory effect of polymyxin B on GRK5 activity (a), and inhibitory mode of polymyxin B (b). The inhibitory activity of polymyxin B was determined by LANCE ${ }^{\circledR}$-TR-FRET as described in the Materials and Methods sections. Staurosporine was used as a reference compound for GRK5 assay. The percent inhibition was calculated as ([raw data of compound - mean $\left.\mathrm{c}^{-}\right] /\left[\right.$mean $\mathrm{c}^{+}-$mean $\left.\mathrm{c}^{-}\right]$) $\times 100$. Data are expressed as the mean \pm S.D. $(n=3)$. Double reciprocal plots of $1 / \mathrm{v}$ versus $1 /[$ ATP] were carried out using varying concentrations of ATP $(5-80 \mu \mathrm{M})$, GRK5 $(0.5 \mu \mathrm{g} / \mathrm{ml})$, and ULight-Histon H3 substrate $(80 \mathrm{nM})$ in the presence or absence of polymyxin B. The initial rate $\mathrm{v}$ was estimated as an amount of phospho-substrate transferred during the reaction period (nM/min). 
plasma membrane localization of GRK5 by interaction with phospholipids [23]. Moreover, GRK5 has a functional nuclear localization sequence and can be found in the nucleus of cells. Recently, GRK5 is newly discovered as a nuclear HDAC kinase that plays a key role in maladaptive cardiac hypertrophy [24]. Therefore, it has been postulated that the inhibition of GRK5 can result in suppression of cardiac hypertrophy. To validate inhibitory effect of polymyxin B on GRK5, IC $_{50}$ value and inhibitory mode of polymyxin B were measured in LANCE $^{\circledR}$-TR-FRET assay, which revealed that polymyxin B possesses a potent ability to inhibit GRK5 with $\mathrm{IC}_{50}$ values of $1.1 \mu \mathrm{M}$ and behaves as an ATP non-competitive inhibitor. This assay was validated with staurosporine, a non-specific kinase inhibitorbecause specific GRK5 inhibitors reported in public have been unknown until now. These results suggest that polymyxin B potently inhibits GRK5 and that by so doing it modulates actin stress fiber formation and cellular hypertrophy.

\section{Conclusion}

In conclusion, our results show for the first time that polymyxin B suppresses the stress fiber formation and cellular hypertrophy in Ang II-stimulated H9c2 cells. In addition, these anti-fibrotic and anti-cellular hypertrophic effects of polymyxin B might be, at least in part, due to the inhibition of GRK5 with ATP non-competitive manner. Further studies are necessary to elucidate the molecular entities directly responsible and other effects of polymyxin B on Ang II-induced proliferation or other growth signaling.

\section{Acknowledgements}

This study was supported by a grant of the Technology Innovation Program (10038744) of Korea Evaluation Institute of Industrial Technology (KEIT), MOTIE, Republic of Korea, and by a grant of the Korea healthcare technology R\&D Project (A100096), MOHW, Republic of Korea.

\section{References}

[1] Chaponnier, C. and Gabbiani, G. (2004) Pathological Situations Characterized by Altered Actin Isoform Expression. Journal of Pathology, 204, 386-395. http://dx.doi.org/10.1002/path.1635

[2] Olivetti, G., Melissari, M., Capasso, J.M. and Anversa, P. (1991) Cardiomyopathy of the Aging Human Heart. Myocyte Loss and Reactive Cellular Hypertrophy. Circulation Research, 68, 1560-1568. http://dx.doi.org/10.1161/01.RES.68.6.1560

[3] Zeidan, A., Javadov, S. and Karmazyn, M. (2006) Essential Role of Rho/ROCK-Dependent Processes and Actin Dynamics in Mediating Leptin-Induced Hypertrophy in Rat Neonatal Ventricular Myocytes. Cardiovascular Research, 72, 101-111. http://dx.doi.org/10.1016/j.cardiores.2006.06.024

[4] Balasubramanian, S., Mani, S.K., Kasiganesan, H., Baicu, C.C. and Kuppuswamy, D. (2010) Hypertrophic Stimulation Increases Beta-Actin Dynamics in Adult Feline Cardiomyocytes. PLoS ONE, 5, e11470. http://dx.doi.org/10.1371/journal.pone.0011470

[5] Oh, K.S., Oh, B.K., Park, C.H., Seo, H.W., Kang, N.S., Lee, J.H., Lee, J.S. and Lee, B.H. (2013) Cardiovascular Effects of a Novel Selective Rho Kinase Inhibitor, 2-(1H-Indazole-5-yl)Amino-4-Methoxy-6-Piperazino Triazine (DW1865). European Journal of Pharmacology, 702, 218-226. http://dx.doi.org/10.1016/j.ejphar.2013.01.027

[6] Moey, M., Rajapurohitam, V., Zeidan, A. and Karmazyn, M. (2011) Ginseng (Panax quinquefolius) Attenuates LeptinInduced Cardiac Hypertrophy through Inhibition of p115Rho Guanine Nucleotide Exchange Factor-RhoA/Rho-Associated, Coiled-Coil Containing Protein Kinase-Dependent Mitogen-Activated Protein Kinase Pathway Activation. Journal of Pharmacology and Experimental Therapeutics, 339, 746-756. http://dx.doi.org/10.1124/jpet.111.182600

[7] Evans, M.E., Feola, D.J. and Rapp, R.P. (1999) Polymyxin B Sulfate and Colistin: Old Antibiotics for Emerging Multiresistant Gram-Negative Bacteria. Annals of Pharmacotherapy, 33, 960-967. http://dx.doi.org/10.1345/aph.18426

[8] Zavascki, A.P., Goldani, L.Z., Li, J. and Nation, R.L. (2007) Polymyxin B for the Treatment of Multidrug-Resistant Pathogens: A Critical Review. Journal of Antimicrobial Chemotherapy, 60, 1206-1215.

http://dx.doi.org/10.1093/jac/dkm357

[9] Murakami, M., Miyauchi, Y., Nishida, M., Okada, H. and Hamano, K. (2009) Direct Hemoperfusion Using Polymyxin-B Immobilized Fiber for Septic Shock after Cardiac Surgery. Circulation Journal, 73, 658-661. http://dx.doi.org/10.1253/circj.CJ-08-0503

[10] Sato, K., Maekawa, H., Sakurada, M., Orita, H. and Komatsu, Y. (2011) Direct Hemoperfusion with Polymyxin B Immobilized Fiber for Abdominal Sepsis in Europe. Surgery Today, 41, 754-760.

http://dx.doi.org/10.1007/s00595-010-4504-9 
[11] Azad, M.A., Finnin, B.A., Poudyal, A., Davis, K., Li, J., Hill, P.A., Nation, R.L., Velkov, T. and Li, J. (2013) Polymyxin B Induces Apoptosis in Kidney Proximal Tubular Cells. Antimicrobial Agents and Chemotherapy, 57, 43294335. http://dx.doi.org/10.1128/AAC.02587-12

[12] Harding, E.A., Jaggar, J.H., Squires, P.E. and Dunne, M.J. (1994) Polymyxin B Has Multiple Blocking Actions on the ATP-Sensitive Potassium Channel in Insulin-Secreting Cells. Pflugers Archiv: European Journal of Physiology, 426, 31-39. http://dx.doi.org/10.1007/BF00374667

[13] Ktenas, T.B., Sotiroudis, T.G. and Evangelopoulos, A.E. (1989) Effects of Polymyxin B on the Sarcoplasmic Reticulum Membrane. Bioscience Reports, 9, 573-578. http://dx.doi.org/10.1007/BF01119800

[14] Aida, Y., Pabst, M.J., Rademacher, J.M., Hatakeyama, T. and Aono, M. (1990) Effects of Polymyxin B on Superoxide Anion Release and Priming in Human Polymorphonuclear Leukocytes. Journal of Leukocyte Biology, 47, $283-291$.

[15] Stutchfield, J., Jones, P.M. and Howell, S.L. (1986) The Effects of Polymyxin B, a Protein Kinase C Inhibitor, on Insulin Secretion from Intact and Permeabilized Islets of Langerhans. Biochemical and Biophysical Research Communications, 136, 1001-1006. http://dx.doi.org/10.1016/0006-291X(86)90432-8

[16] Xu, F., Dai, C.L., Peng, S.L., Zhao, Y., Jia, C.J., Xu, Y.Q. and Zhao, C. (2014) Polymyxin B Protects against Hepatic Ischemia/Reperfusion Injury in a Rat Model of Obstructive Jaundice. Inflammation, 37, 1015-1021. http://dx.doi.org/10.1007/s10753-014-9822-4

[17] Gysembergh, A., Margonari, H., Loufoua, J., Ovize, A., André-Fouët, X., Minaire, Y. and Ovize, M. (1998) StretchInduced Protection Shares a Common Mechanism with Ischemic Preconditioning in Rabbit Heart. American Journal of Physiology-Heart and Circulatory Physiology, 274, H955-H964.

[18] Yelich, M.R., Schieber, C.K., Umporowicz, D.M. and Filkins, J.P. (1992) Polymyxin-B Suppresses Endotoxin-Induced Insulin Hypersecretion in Pancreatic Islets. Circulatory Shock, 38, 85-90.

[19] McKinsey, T.A. and Kass, D.A. (2007) Small-Molecule Therapies for Cardiac Hypertrophy: Moving beneath the Cell Surface. Nature Reviews Drug Discovery, 6, 617-635. http://dx.doi.org/10.1038/nrd2193

[20] Sin, Y.Y. and Baillie, G.S. (2012) Protein Kinase D in the Hypertrophy Pathway. Biochemical Society Transactions, 40, 287-289. http://dx.doi.org/10.1042/BST20110626

[21] Belmonte, S.L. and Blaxall, B.C. (2012) G Protein-Coupled Receptor Kinase 5: Exploring Its Hype in Cardiac Hypertrophy. Circulation Research, 111, 957-958. http://dx.doi.org/10.1161/CIRCRESAHA.112.278432

[22] Ishizaka, N., Alexander, R.W., Laursen, J.B., Kai, H., Fukui, T., Oppermann, M., Lefkowitz, R.J., Lyons, P.R. and Griendling, K.K. (1997) G Protein-Coupled Receptor Kinase 5 in Cultured Vascular Smooth Muscle Cells and Rat Aorta. Regulation by Angiotensin II and Hypertension. Journal of Biological Chemistry, 272, 32482-32488. http://dx.doi.org/10.1074/jbc.272.51.32482

[23] Thiyagarajan, M.M., Stracquatanio, R.P., Pronin, A.N., Evanko, D.S., Benovic, J.L. and Wedegaertner, P.B. (2004) A Predicted Amphipathic Helix Mediates Plasma Membrane Localization of GRK5. Journal of Biological Chemistry, 279, 17989-17995. http://dx.doi.org/10.1074/jbc.M310738200

[24] Martini, J.S., Raake, P., Vinge, L.E., DeGeorge Jr., B.R., Chuprun, J.K., Harris, D.M., Gao, E., Eckhart, A.D., Pitcher, J.A. and Koch, W.J.(2008) Uncovering G Protein-Coupled Receptor Kinase-5 as a Histone Deacetylase Kinase in the Nucleus of Cardiomyocytes. Proceedings of the National Academy of Sciences of the United States of America, 105, 12457-12462. http://dx.doi.org/10.1073/pnas.0803153105

\section{Abbreviations}

Ang II: Angiotensin II

DMEM: Dulbecco's Modified Eagle’s Medium

GRK5: G Protein Related Kinase 5

HDAC5: Histone Deacetylase 5

TR-FRET: Time-Resolved Fluorescence Resonance Energy Transfer 
Scientific Research Publishing (SCIRP) is one of the largest Open Access journal publishers. It is currently publishing more than 200 open access, online, peer-reviewed journals covering a wide range of academic disciplines. SCIRP serves the worldwide academic communities and contributes to the progress and application of science with its publication.

Other selected journals from SCIRP are listed as below. Submit your manuscript to us via either submit@scirp.org or Online Submission Portal.
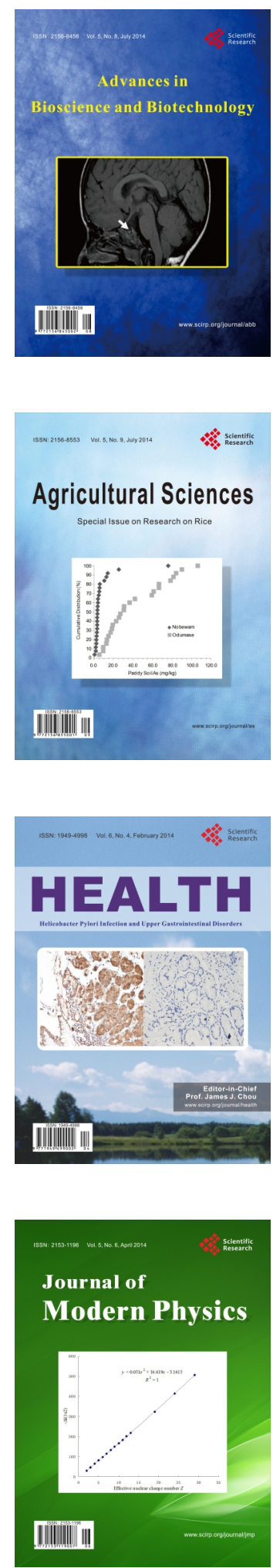
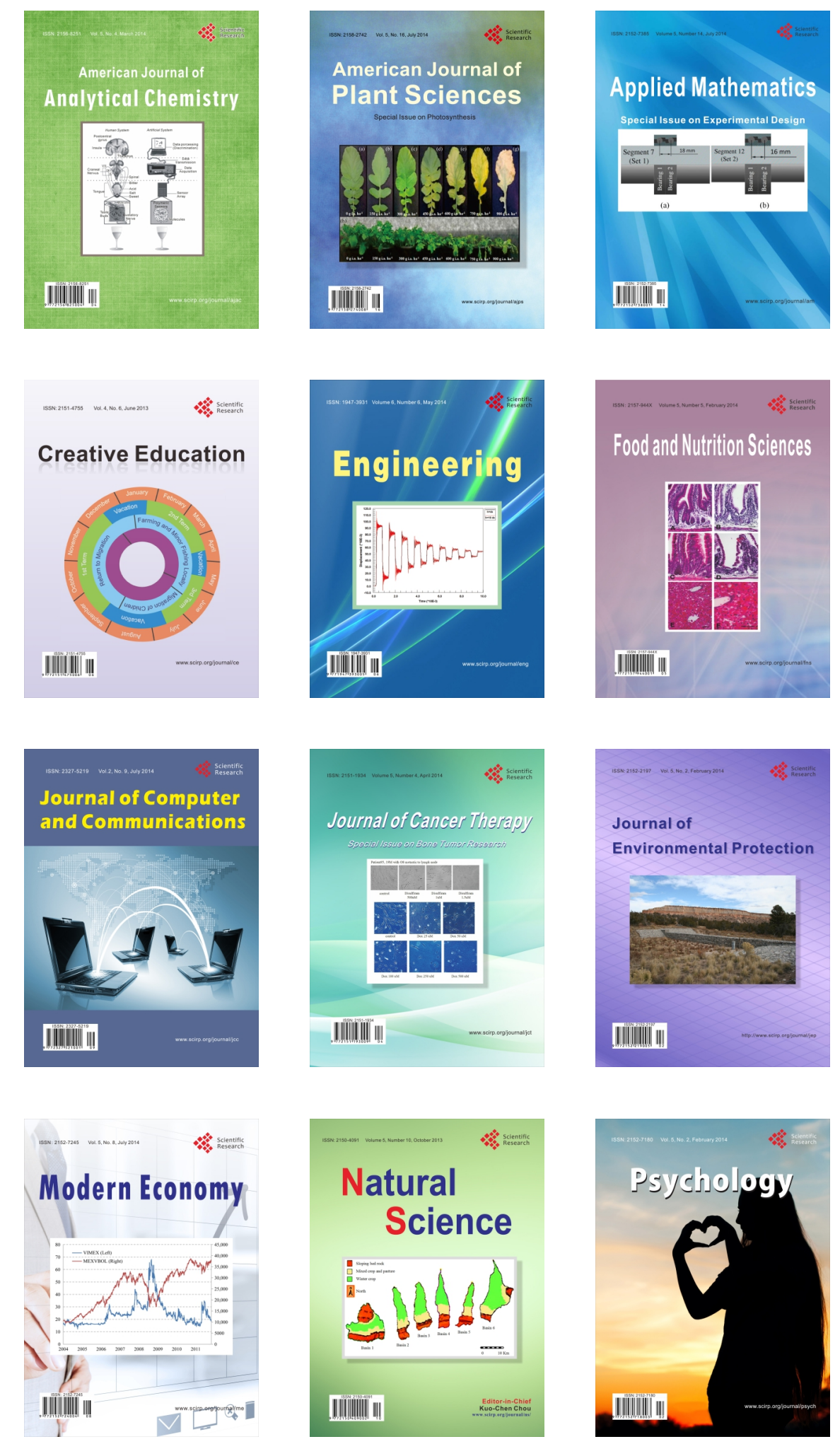